Thorax (1948), 3, 127.

\title{
HAEMORRHAGE AFTER EXTRAPLEURAL PNEUMONOLYSIS
}

\author{
BY \\ W. P. C.LELAND
}

London

Moderate or massive haemorrhage into the extrapleural space within a few days of the performance of an extrapleural pneumonolysis occurs in from 5 per cent to 20 per cent of cases. It may give rise to few symptoms, or be severe enough to cause alarming collapse of the patient and justify, if not demand, immediate transfusion. Apart from the immediate and more alarming physiological disturbances, delayed infection or gradual obliteration of the space may imperil the success of the operation.

Hugh Reid (1946), however, in recording his experiences with fifty-four cases, states that only one case had a post-operative haemorrhage which required a blood transfusion. Cases were encountered, however, where the extrapleural space was found to be completely opaque after operation and yet no blood could be aspirated; when the space was explored through an adequate incision blood clot was found and readily removed.

\section{Branches of the InTernal Mammary ARTery}

Recently when re-operating on an extrapleural pneumothorax which had re-expanded completely soon after operation, I introduced a needle at the - site where refills had been given, in order to determine its relationships to the pleural reflection. The needle, by chance, punctured one of a leash of vessels arising from the internal mammary artery and coursing unsupported on the inner chest wall ; the spurt of blood was sufficient to traverse the extrapleural space and impinge on the opposite wall. It seemed that the puncture of one of these vessels when giving a refill may account for some, at any rate, of the post-operative haemorrhages, especially if the accident occurred early when the vessels were lying unsupported on the wall of the space so that neither retraction of the vessel wall nor clot formation could occur.

The standard British anatomical textbooks do not refer to branches of the internal mammary artery coursing over the inner aspect of the thoracic cage, but Piersol (1930) states " of the supernumerary branches to which it (the internal mammary artery) gives rise, one of the most im- portant is the lateral costal branch (ramus costalis lateralis). This arises from the internal mammary above the first rib, or in some cases from the subclavian, and descends upon the inner surfaces of the upper four or six ribs and the intervening intercostal spaces, parallel with the internal mammary, but some distance lateral to it. It gives off branches in each intercostal space, which anastomose ventrally with the anterior intercostal branches of the internal mammary and dorsally with the aortic intercostals."

Deaver (1927) describes a lateral infracostal artery which "arises near the first rib and descends behind the ribs just outside their junction with the costal cartilages. It is small in size and not constant."

I have tried to determine the exact anatomical course of the vessels concerned and the frequency with which one can expect to find them. My observations have been made on the cadaver, in performing thoracoplasties and extrapleural pneumothoraces, and in examining the region at thoracoscopy performed for the division of adhesions.

- In seventy cases where the region could be carefully examined at thoracoscopy, forty-two showed well-marked lateral costal branches of the internal mammary artery. In several cases visible pulsation was obvious, whilst in others a leash of six vessels could be seen, representing two branches of the artery and paired vanae comites ; these vessels covered quite a wide area. Thoracoscopic cannulae placed in the axilla through the third or fourth spaces may occasionally pierce one of these vessels, and, if this fact were unsuspected or the bleeding uncontrolled, it would account for some instances of haemothorax after adhesion section.

Performing extrafascial apicolysis with thoracoplasty, I have in almost every instance encountered a branch of the internal mammary artery arising from the parent trunk as it crosses the innominate vein ; this branch is divided when performing apicolysis and requires either ligation or coagulation to control it. I have, however, encountered it only five times during the performance of twelve recent extrapleural pneumolyses. 
Observations on two out of five cadavers examined have shown this vessel obviously traceable and with a fairly constant course; in one instance it was present only on one side. It arises from the internal mammary artery $2 \mathrm{~cm}$. from its origin as the latter crosses the innominate vein. It proceeds laterally and downwards almost at right angles to the parent trunk (see diagram) to cross the first rib 1 to $2 \mathrm{~cm}$.

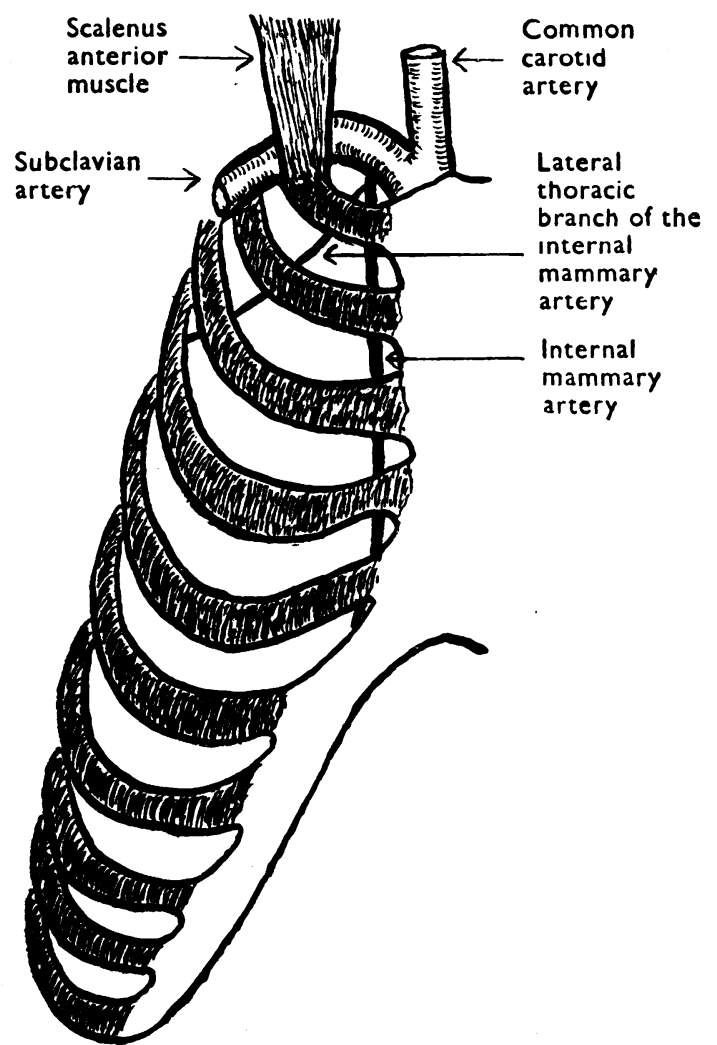

Diagram of the bony thorax to illustrate the origin and course of the lateral costal branch of the internal mammary artery.

from the costochondral junction, the second rib $8 \mathrm{~cm}$. from the sternal edge, and the third rib $10 \mathrm{~cm}$. from the sternal edge. Externally the points marking its course lie $5 \mathrm{~cm}$. laterally from the inner end of the clavicle, $8 \mathrm{~cm}$. from the sternal edge at the level of the second rib, and $11 \mathrm{~cm}$. from the sternal edge on the third rib. It crosses the first space at approximately the mid-clavicular line, and the third rib at the anterior axillary line.

This description does not quite coincide with those given either by Piersol or Deaver, who respectively describe the vessel running parallel with the internal mammary and just outside the costochondral junction, but there seems little doubt that they are describing the same vessel ; it is probably easier to trace its course in life when the veins are well distended rather than when they are collapsed and empty as in the cadaver.

From this description it will be appreciated that the lateral costal vessels pass across the area usually selected for refills of air after the performance of an extrapleural pneumonolysis. They should, therefore, be sought at the conclusion of the operation, and if present should be ligated or coagulated by diathermy ; in addition, refills should preferably be given from the back for the first two to three weeks after operation until the vessels have acquired support and covering on their inner aspect.

\section{Summary AND CONClusions}

1. Lateral thoracic branches of the internal mammary occur in approximately 50 per cent of individuals.

2. These vessels course over the inner aspect of the upper and antero-lateral aspect of the chest wall.

3. They may be damaged when giving refills after an extrapleural pneumonolysis, and cause serious haemorrhage into the extrapleural space.

4. When discovered at operation the vessels should be ligated or coagulated with diathermy, and in addition refills should at first be given from the back.

\section{REFERENCES}

Deaver, J. B. (1927). "Surgical Anatomy," vol. 3, p. 124. London.

Piersol, G. A. (1930). "Human Anatomy," 9th edition, p. 764. Philadelphia.

Reid, H. (1946). Thorax, 1, 211. 